Supporting information for

\title{
Olefin Epoxidation by the Hydrogen Peroxide Adduct of a Novel Non-heme Mangangese(IV) \\ Complex: Demonstration of Oxygen Transfer by Multiple Mechanisms \\ Guochuan Yin ${ }^{\dagger}$, Maria Buchalova ${ }^{\dagger}$, Andrew M. Danby ${ }^{\dagger}$, Chris M. Perkins ${ }^{\ddagger}$, David Kitko ${ }^{\ddagger}$, John Carter ${ }^{\ddagger}$, William M. Scheper ${ }^{\ddagger}$ and Daryle H. Busch ${ }^{\dagger *}$ \\ †The University of Kansas, Department of Chemistry, Lawrence, Kansas 66045. "The Procter and Gamble Company,
}

Cincinnati, Ohio 45202.

Properties of hydrogen peroxide in acetone. The reaction between $\mathrm{H}_{2} \mathrm{O}_{2}$ and acetone to form 2hydroxy-2-hydroperoxypropane is well documented, and the equilibrium constant for formation of this acetone adduct was found to be $\mathrm{K}=0.086 \mathrm{M}^{-1}$ at $25^{\circ} \mathrm{C}$. According to this equilibrium constant, under our reaction conditions $\left(0.25 \mathrm{~mL}\right.$ of $30 \% \mathrm{H}_{2} \mathrm{O}_{2}$ in $5 \mathrm{~mL}$ of acetone/water (ratio $\left.4: 1\right)$ ), $\sim 50 \%$ of $\mathrm{H}_{2} \mathrm{O}_{2}$ exists as the acetone adduct (eq1). However, this 2-hydroxy-2-hydroperoxypropane compound is not capable of direct epoxidation of olefins since the baseline experiment, treating olefin with $\mathrm{H}_{2} \mathrm{O}_{2}$ in acetone/water (ratio 4:1) without catalyst, produces no conversion of olefin to epoxide. Furthermore, Que's work demonstrated that oxidation of cyclooctene with $\mathrm{Fe}^{\mathrm{II}}$ (tpa) catalyst by $\mathrm{H}_{2} \mathrm{O}_{2}$ in acetone or acetonitrile provided similar product distributions, and the complexation reaction between 2-hydroxy-2hydroperoxypropane and Que's catalyst formed an adduct that is not active in oxidation, indicating that 2-hydroxy-2-hydroperoxypropane was not involved in the epoxidation reactions. ${ }^{2}$ In addition, dimethyl dioxirane, a known active intermediate in ketone catalyzed epoxidation reactions, ${ }^{3}$ is also not involved in epoxidation under our reaction condition (see parallel experiment without catalyst).

$$
\mathrm{CH}_{3} \mathrm{COCH}_{3}+\mathrm{H}_{2} \mathrm{O} \leftarrow \rightarrow \mathrm{CH}_{3}(\mathrm{OH}) \mathrm{C}(\mathrm{OOH}) \mathrm{CH}_{3} \quad \text { eq } 1
$$

\section{References}

1. Sauer, M.C. V., Edwards, J. O. J. Phys. Chem. 1971, 75, 3004.

2. Payeras, A. M., Ho, R. Y. N., Fujita, M., Que, Jr. L. Chem. Eur. J. 2004, 10, 4944.

3. Wang, Z., Tu, Y., Frohn, M., Zhang, J., Shi, Y. J. Am. Chem. Soc. 1997, 119, 11224. 


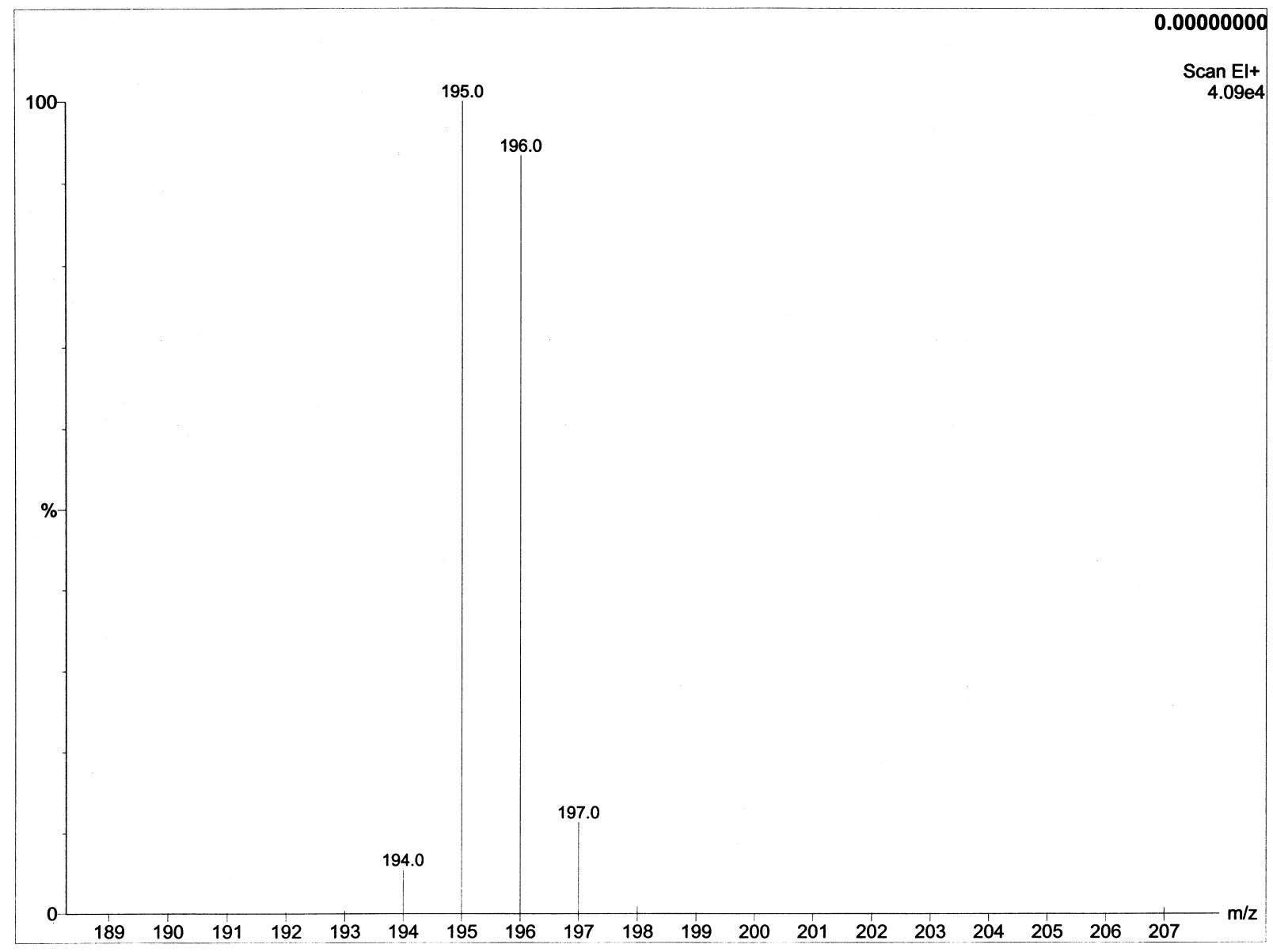

Figure S1 GC/MS graph of cis-stilbene oxide from epoxidation of cis-stilbene with $\mathrm{Mn}\left(\mathrm{Me}_{2} \mathrm{EBC}\right) \mathrm{Cl}_{2} / \mathrm{H}_{2} \mathrm{O}_{2} / \mathrm{H}_{2} \mathrm{O}$ under air. 


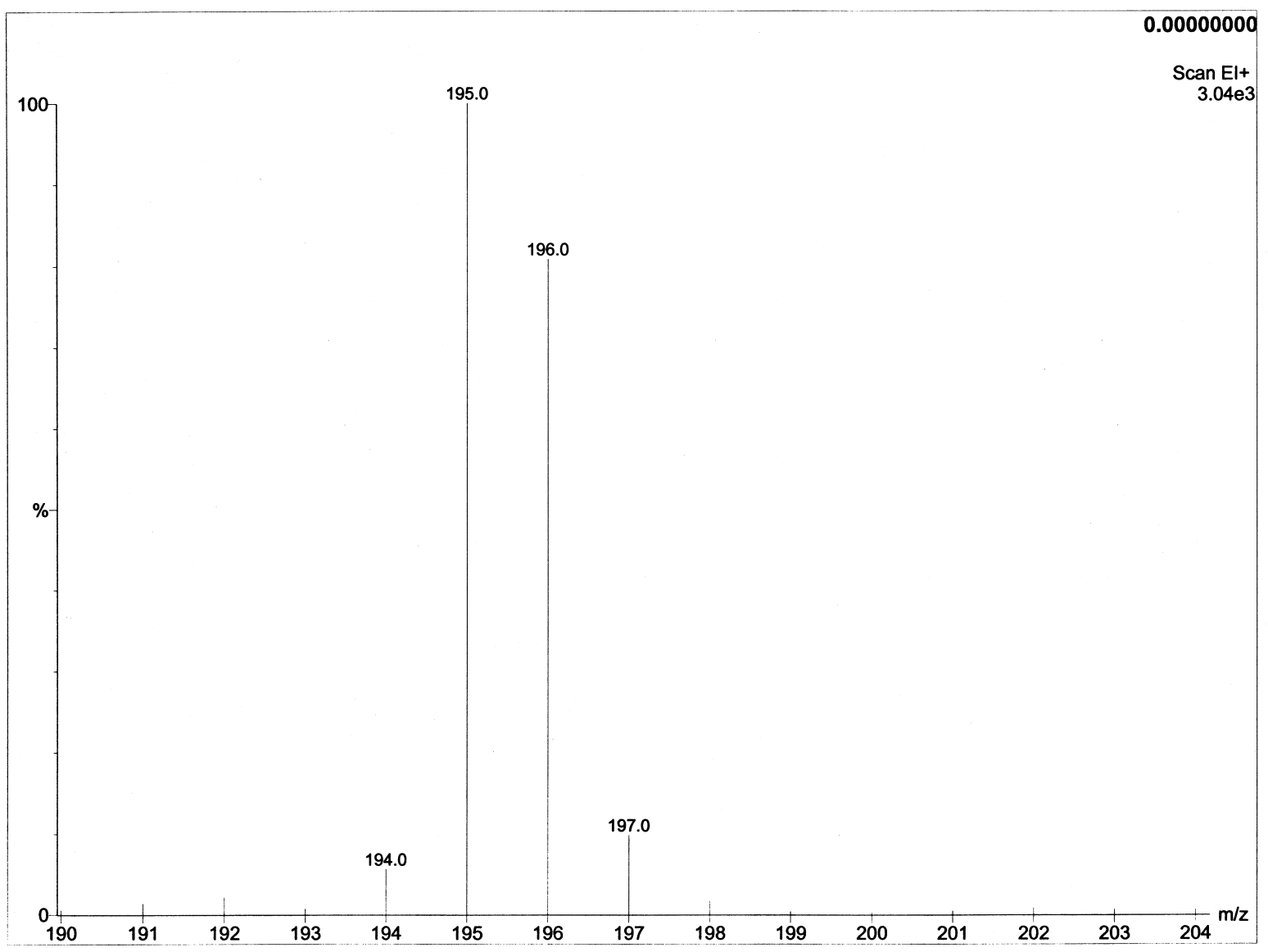

Figure S2 GC/MS graph of trans-stilbene oxide from epoxidation of cis-stilbene with $\mathrm{Mn}\left(\mathrm{Me}_{2} \mathrm{EBC}\right) \mathrm{Cl}_{2} / \mathrm{H}_{2} \mathrm{O}_{2} / \mathrm{H}_{2} \mathrm{O}$ under air. 


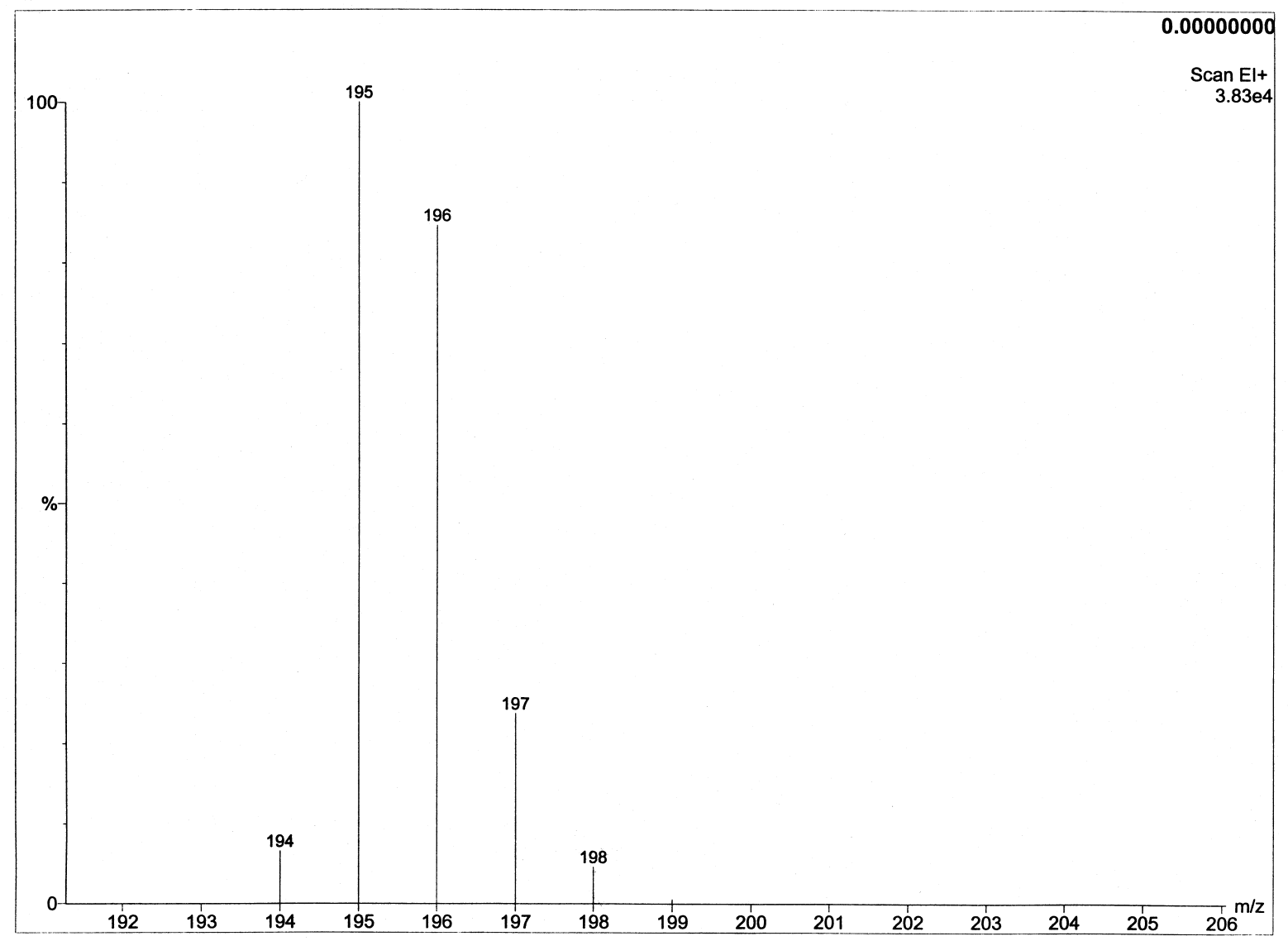

Figure S3 GC/MS graph of cis-stilbene oxide from epoxidation of cis-stilbene with $\mathrm{Mn}\left(\mathrm{Me}_{2} \mathrm{EBC}\right) \mathrm{Cl}_{2} / \mathrm{H}_{2} \mathrm{O}_{2} / \mathrm{H}_{2}{ }^{18} \mathrm{O}$ under air. 


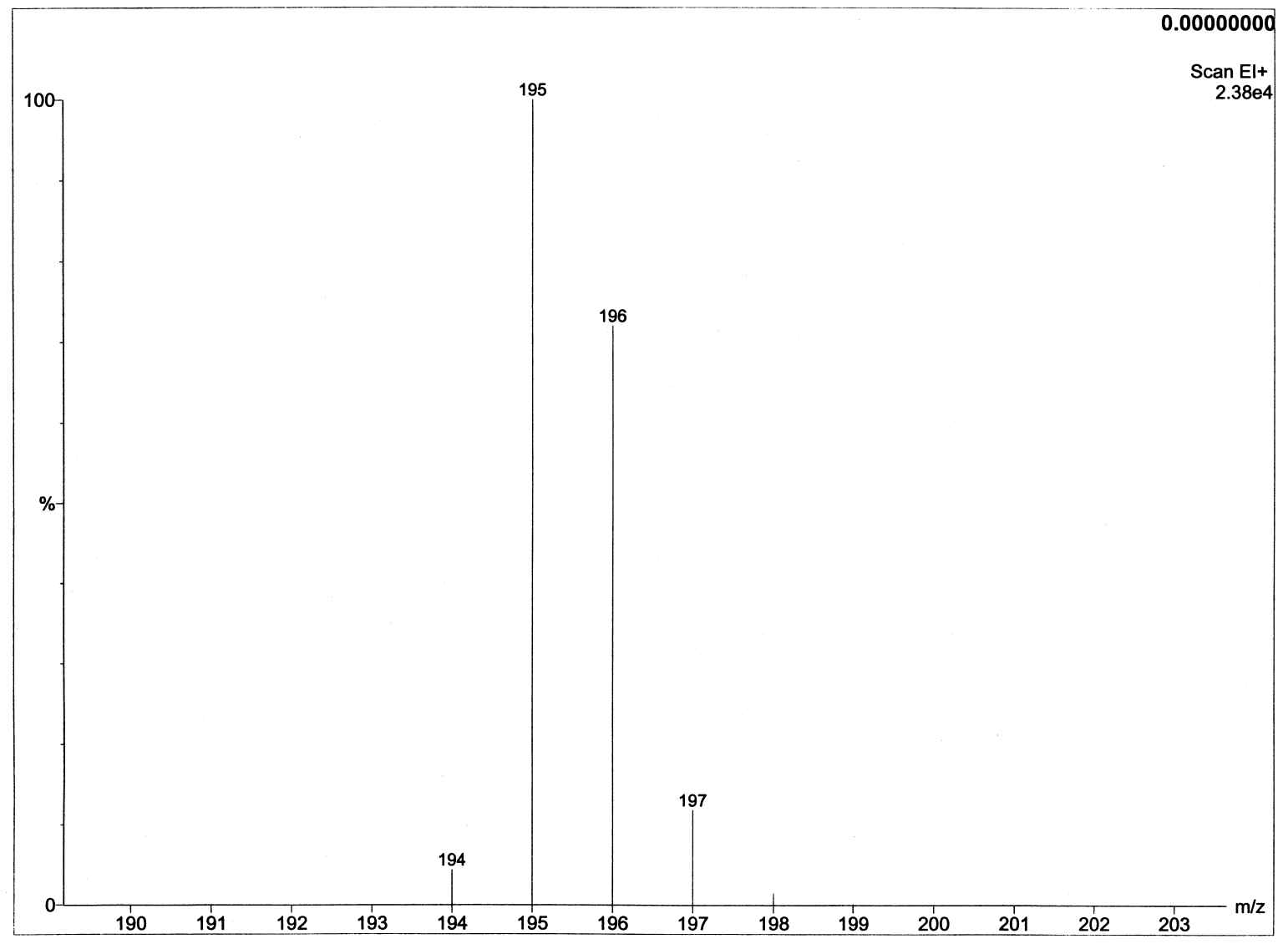

Figure S4 GC/MS graph of trans-stilbene oxide from epoxidation of cis-stilbene with $\mathrm{Mn}\left(\mathrm{Me}_{2} \mathrm{EBC}\right) \mathrm{Cl}_{2} / \mathrm{H}_{2} \mathrm{O}_{2} / \mathrm{H}_{2}{ }^{18} \mathrm{O}$ under air. 


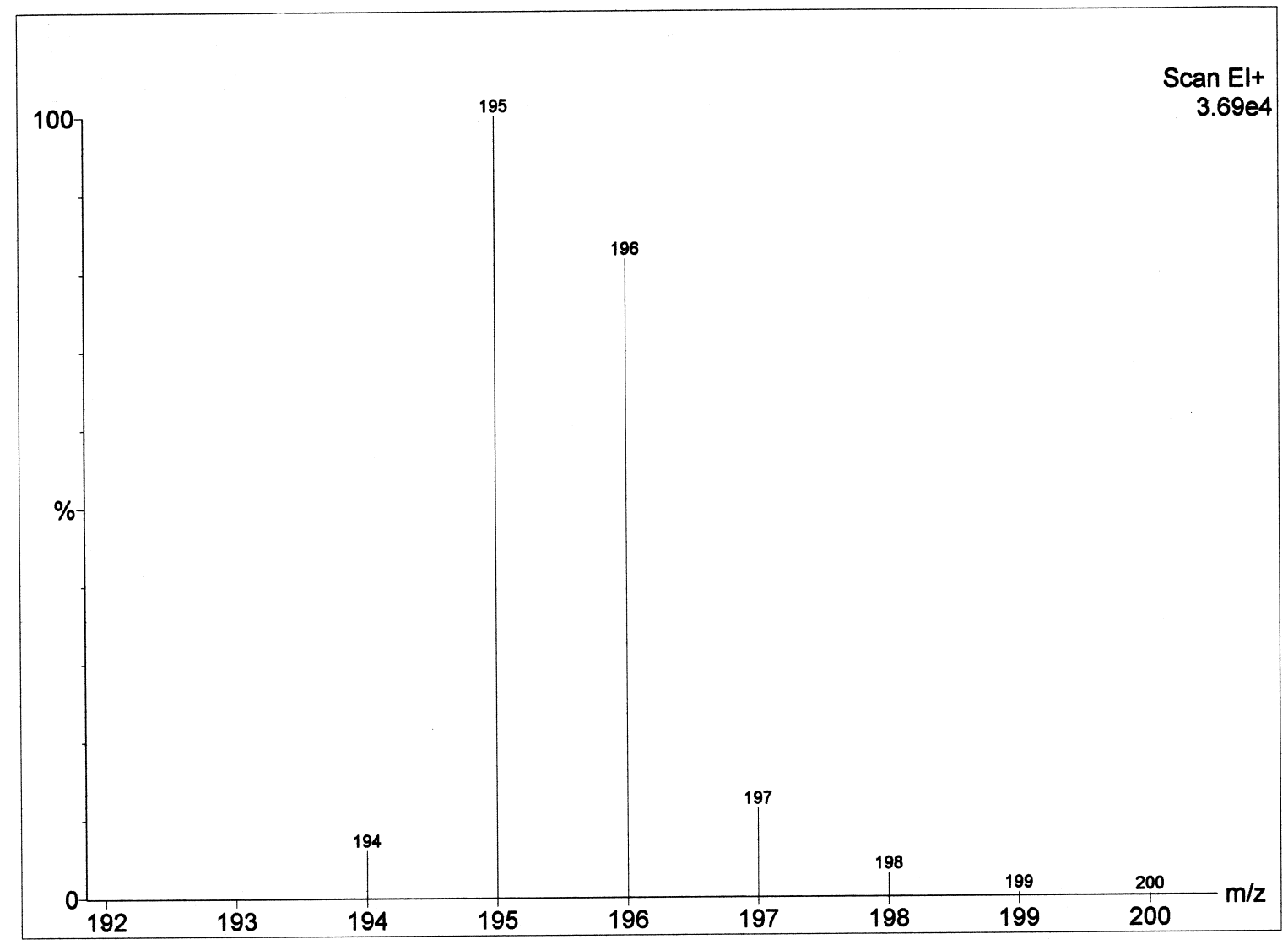

Figure S5 GC/MS graph of cis-stilbene oxide from epoxidation of cis-stilbene with $\mathrm{Mn}\left(\mathrm{Me}_{2} \mathrm{EBC}\right) \mathrm{Cl}_{2} / \mathrm{H}_{2} \mathrm{O}_{2} / \mathrm{H}_{2} \mathrm{O}$ under ${ }^{18} \mathrm{O}_{2}$. 


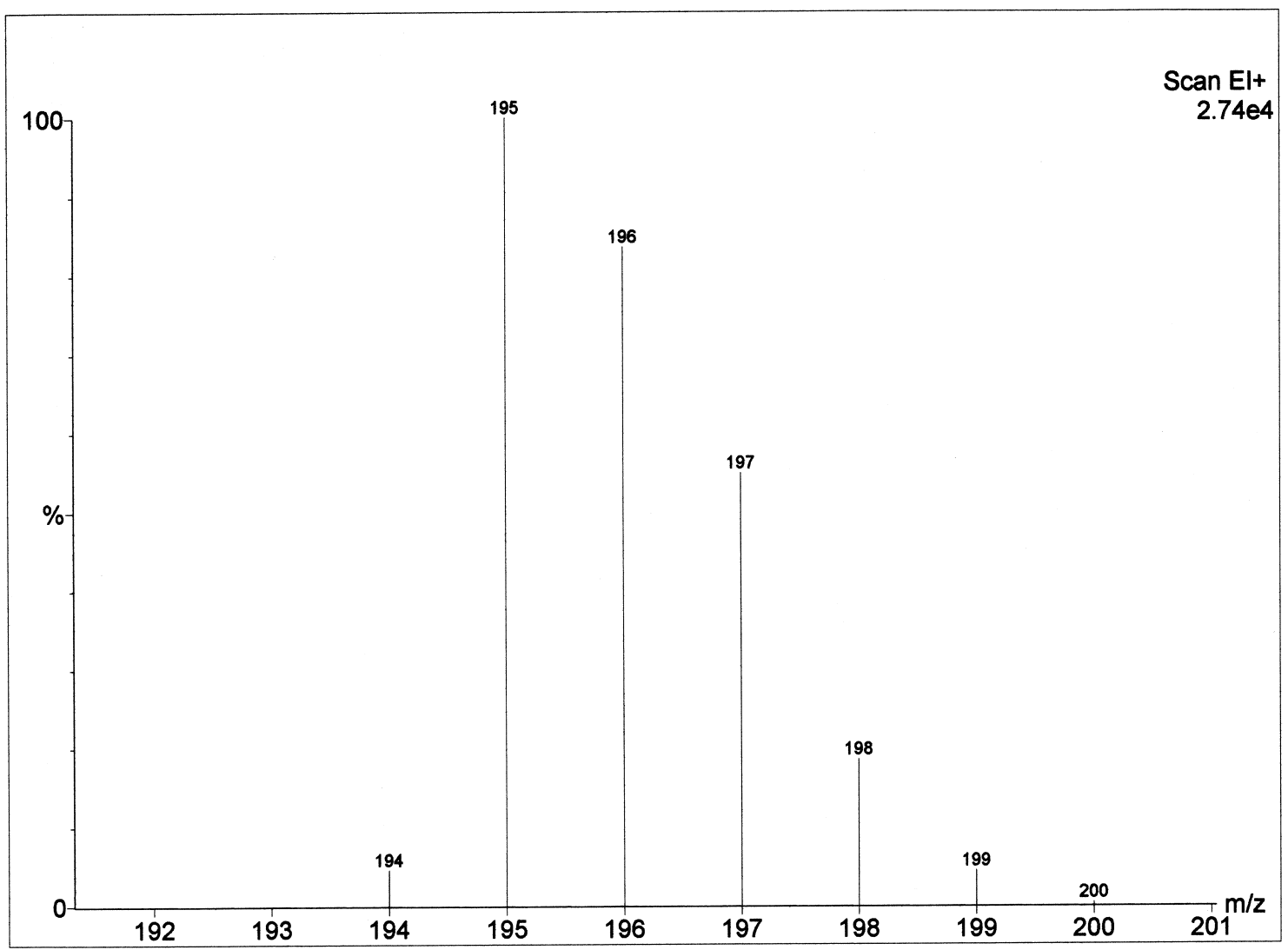

Figure S6 GC/MS graph of trans-stilbene oxide from epoxidation of cis-stilbene with $\mathrm{Mn}\left(\mathrm{Me}_{2} \mathrm{EBC}\right) \mathrm{Cl}_{2} / \mathrm{H}_{2} \mathrm{O}_{2} / \mathrm{H}_{2} \mathrm{O}$ under ${ }^{18} \mathrm{O}_{2}$. 


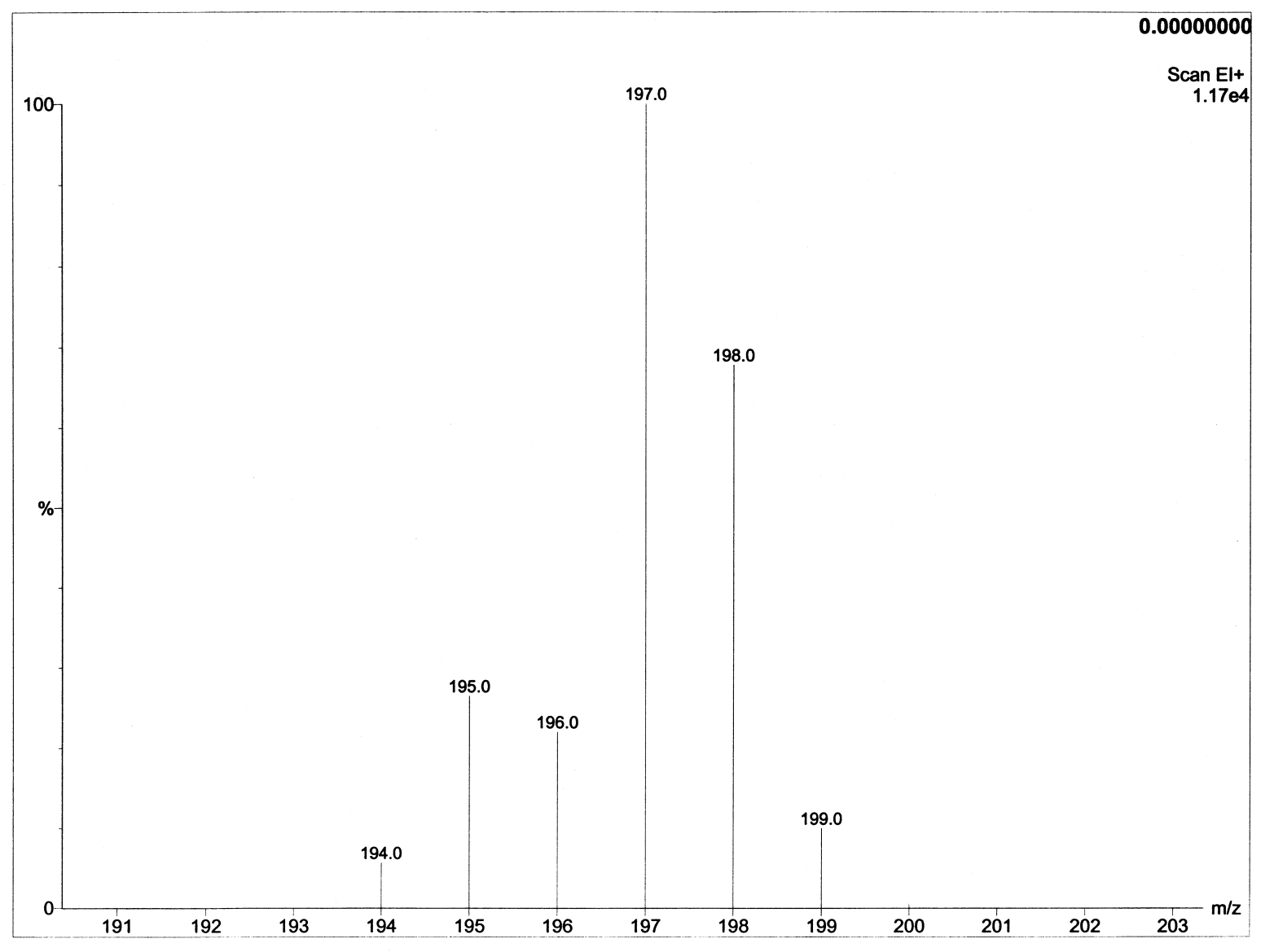

Figure S7 GC/MS graph of cis-stilbene oxide from epoxidation of cis-stilbene with $\mathrm{Mn}\left(\mathrm{Me}_{2} \mathrm{EBC}\right) \mathrm{Cl}_{2} / \mathrm{H}_{2}{ }^{18} \mathrm{O}_{2} / \mathrm{H}_{2} \mathrm{O}$ under air. 


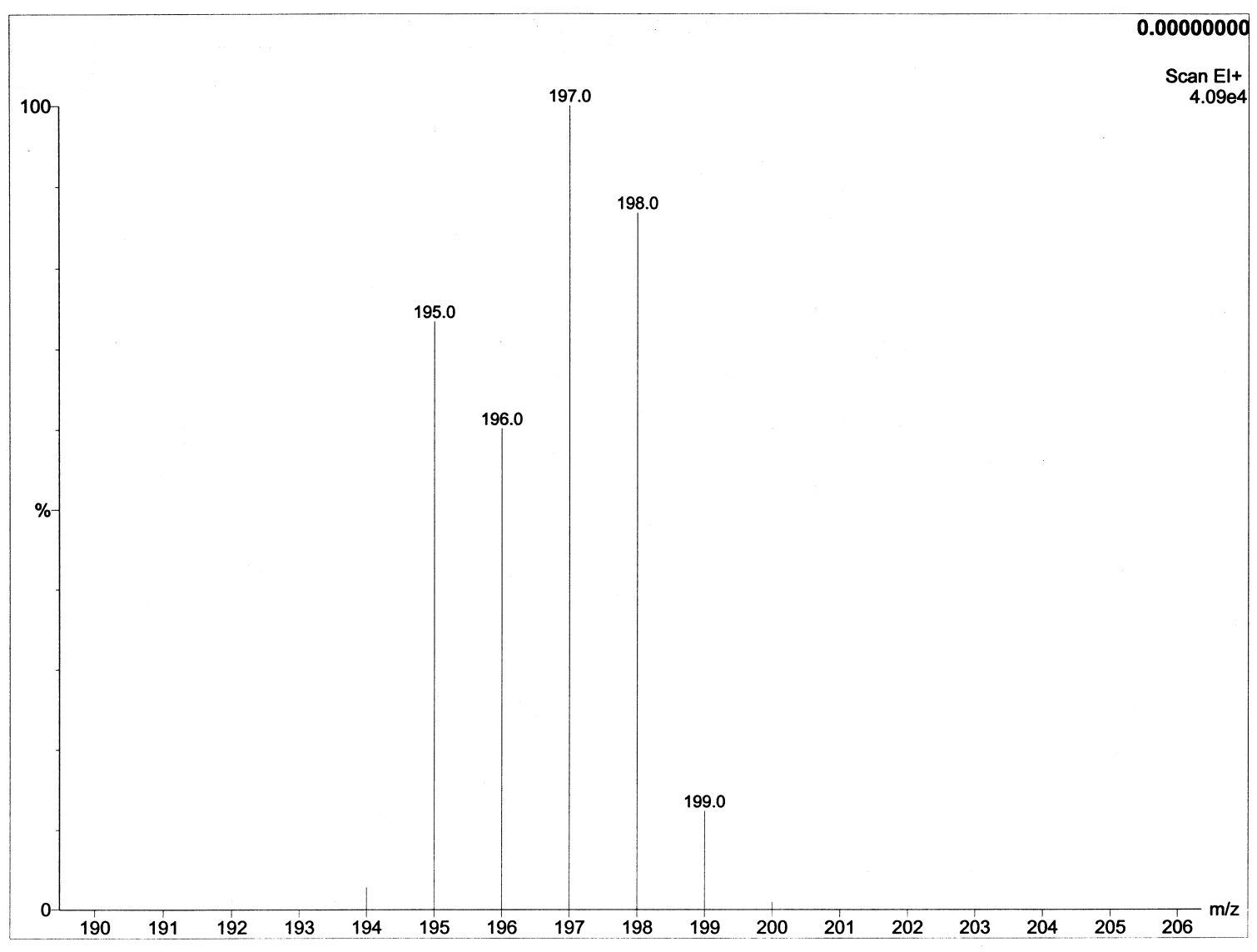

Figure S8 GC/MS graph of trans-stilbene oxide from epoxidation of cis-stilbene with $\mathrm{Mn}\left(\mathrm{Me}_{2} \mathrm{EBC}\right) \mathrm{Cl}_{2} / \mathrm{H}_{2}{ }^{18} \mathrm{O}_{2} / \mathrm{H}_{2} \mathrm{O}$ under air. 